\title{
THELEP controlled clinical trials in lepromatous leprosy*
}

\begin{abstract}
Subcommittee on Clinical Trials of the Chemotherapy of Leprosy (THELEP) Scientific Working Group of the UNDP/World Bank/ WHO Special Programme for Research and Training in Tropical Diseases

Summary The events leading to the development of the THELEP Standard Protocol for controlled clinical trials in lepromatous leprosy are recounted, and the structure of the Standard Protocol is described. Trials of multidrug regimens including dapsone, rifampicin and clofazimine or prothionamide have been undertaken in Bamako and Chingleput.
\end{abstract}

Members of the THELEP Clinical Trials Subcommittee are:

Dr G A Ellard, National Institute for Medical Research, London, England,

Dr C A P Ferracci, Institut Marchoux, Bamako, Mali,

Dr C G S Iyer, Central Leprosy Teaching and Research Institute, Chingleput, South India,

Dr Kyaw Lwin, Ministry of Health, Rangoon, Burma,

Dr D L Leiker, Royal Tropical Institute, Amsterdam, Netherlands,

Dr L Levy, Hebrew University-Hadassah Medical School, Jerusalem, Israel,

Dr N E Morrison, The Johns Hopkins University School of Hygiene and Public Health, Baltimore, Maryland, USA,

Dr S K Noordeen, World Health Organization, Geneva, Switzerland,

Dr S R Pattyn, Prince Leopold Institute for Tropical Medicine, Antwerp, Belgium,

Dr J M H Pearson, Dhoolpet Leprosy Research Centre, Hyderabad, India,

Dr R J W Rees, National Institute for Medical Research, London, England,

Dr H Sansarricq, World Health Organization, Geneva, Switzerland,

Dr P S Seshadri, Central Leprosy Teaching and Research Institute, Chingleput, South India,

Dr J K Seydel, Borstel Research Institute, Borstel, Federal Republic of Germany, Dr C C Shepard, Centers for Disease Control, Atlanta, Georgia, USA,

Dr J Walter, World Health Organization, Geneva, Switzerland, Dr M F R Waters, Hospital for Tropical Diseases, London, England.

* This report was prepared by Dr L Levy. 


\section{Introduction}

Modern chemotherapy of leprosy may be said to have begun in 1941, when the first eff ective antimicrobial drug, glucosulphone $\left(\operatorname{Promin}^{\circledR}\right)$, was employed in the treatment of patients with leprosy. ${ }^{5}$ During the next 20 years, a number of other sulphones were introduced into the therapy of leprosy. However, despite the lack during this period of a precise means of measuring the efficacy of chemotherapy, the potency of sulphones became firmly established, and dapsone became accepted as the drug of choice.

\section{MOR PHOLOGICAL INDEX}

The scientific basis of modern leprosy chemotherapy depends upon the development of 2 laboratory techniques that made it possible to measure the rate at which Mycobacterium leprae were killed during treatment. After earlier workers had called attention to morphological changes of $M$. leprae during treatment of leprosy patients, quantitive assessment of the bacterial morphology was introduced as a means of measuring the response of patients to treatment, and employed in a series of clinical trials carried out at Sungei Buloh, Malaysia. ${ }^{10-12,23-26}$ Although the efficacy of treatment by several drugs was demonstrated by observing the decrease of the morphological index (MI), as this measurement came to be known, this decrease of the MI appeared to be a rather insensitive measure of the response to antimicrobial chemotherapy. For example, the rate of decrease of the MI was no more rapid during treatment with dapsone or clofazimine in full dosage than during treatment by much smaller dosages of these drugs. In fact, there is evidence that killing of $M$. leprae is not the rate-determining step in the morphological changes that accompany death of the organisms. ${ }^{19}$

\section{MOUSE FOOT-PAD INOCULATION}

The second laboratory method that contributed uniquely to the development of modern chemotherapy was Shepard's mouse foot-pad technique. ${ }^{16}$ Application of this technique to the measurement of the rate at which M. leprae are killed during effective antimicrobial treatment of the patient with lepromatous leprosy provided a more sensitive and discriminating means of assessing the efficacy of antimicrobial chemotherapy. Employing this technique, a series of clinical trials was carried out in San Francisco and in Cebu. ${ }^{1,2,7,8,17-20}$ These trials established that $M$. leprae recovered from the lesions of patients with lepromatous leprosy lost their infectivity for immunologically normal mice after treatment for an average of 100 days with 50-100 $\mathrm{mg}$ dapsone daily; after an average of 150 days with clofazimine, $100-200 \mathrm{mg}$ daily or $100 \mathrm{mg} 3$ times weekly; af ter more than 150 days of treatment with acedapsone, $225 \mathrm{mg}$ intramuscularly every 77 days, or 
clofazimine, $600 \mathrm{mg}$ every 2 weeks or $1200 \mathrm{mg}$ every 4 weeks; and within a few days of single $600-1500 \mathrm{mg}$ or daily $300-600 \mathrm{mg}$ doses of rifampicin.

Immunologically normal mice appear to mount an effective immune response, causing multiplication to cease when the number of $M$. leprae approaches $1-2 \times 10^{6}$ per foot-pad. M. leprae fail to multiply when $10^{5}$ or more are inoculated into the foot-pad of the normal mouse, and inocula must contain no more than $10^{4}$ organisms per foot-pad, if multiplication is to be recognized reliably. Therefore, failure of multiplication in mice inoculated with $10^{4} \mathrm{M}$. leprae implies only that the inoculum included fewer than 1 viable organism per $10^{4}$ inoculated. Because a patient with lepromatous leprosy who has not been previously treated may harbour as many as $10^{11} \mathrm{M}$. leprae, of which $10 \%\left(10^{10}\right)$ may be viable, he may harbour a great many viable organisms when, in the course of effective treatment, the first $99.9 \%$ of the patient's organisms have been killed, and his $M$. leprae are no longer capable of infecting normal mice. ${ }^{3}$

Thus, although application of the foot-pad technique employing immunologically normal mice to the measurement of chemotherapeutic efficacy produced much important information, the technique possessed important limitations. Thus, whereas this technique showed that single doses of rifampicin killed $M$. leprae as rapidly as could be measured, it was not sensitive enough to show how much more rapidly a combination of rifampicin with another bactericidal drug would kill the organisms, or the rate at which $M$. leprae would be killed, once the patient's organisms were no longer infective for normal mice.

\section{RECOGNITION OF PERSISTING $M . L E P R A E$}

At least a partial answer to the second question was given by studies employing T-cell depleted (adult-thymectomized, whole body-irradiated, and bonemarrow-reconstituted, 'TR') mice, which had been shown by Rees ${ }^{13}$ regularly to permit multiplication after inoculation of $10^{5} \mathrm{M}$. leprae per foot-pad. The first clinical trials undertaken, at Sungei Buloh, with inoculation of T900R mice demonstrated the presence of 'persisting' $M$. leprae. ${ }^{6,14,27}$ (Briefly, persisting $M$. leprae are organisms that survive treatment by ordinarily effective dosages of drugs, despite being fully susceptible to the antimicrobial effects of the drugs; this subject has been recently reviewed by Toman. $)^{22}$ Viable $M$. leprae were detected by inoculation of TR mice with organisms recovered from the tissues of patients after 10 years of supervised treatment with dapsone in full dosage, after 5 years of treatment with rifampicin, $600 \mathrm{mg}$ daily, and after treatment for 6 months by rifampicin, $600 \mathrm{mg}$ daily, administered in combination with dapsone in a daily dose of $100 \mathrm{mg}$.

\section{BEGINNINGS OF THE THELEP PROGRAMME}

Thus, the situation confronting the committee convened in April 1976 to plan the THELEP programme ${ }^{28}$ was as follows. As the result of a number of clinical trials 
employing inoculation of normal mice, dapsone, acedapsone, clofazimine, rifampicin and ethionamide had all been shown, in various dosages, to be effective antimicrobial drugs for the treatment of patients with lepromatous leprosy. Moreover, by the use of TR mice, the ubiquity of persisting $M$. leprae had been demonstrated. It appeared that, in the course of effective chemotherapy of lepromatous leprosy, $M$. leprae were initially killed more or less rapidly; after the initial kill, however, there remained a number of persisting organisms, which was too small to be detected by inoculating normal mice with $10^{4}$ organisms per foot-pad, but could sometimes be detected by inoculating TR mice with $10^{5}$ organisms per foot-pad. It was not clear whether the number of persisters was smaller after treatment by some regimens than it was after treatment by others.

Another problem confronting the THELEP planning committee was that of resistance to dapsone, ${ }^{9}$ the scope of which had been revealed as a result of an application of the mouse foot-pad technique. It was clear that treatment of patients with combinations of drugs was required to prevent the emergence of drug resistance. Whether some combinations would be more eff ective than others in decreasing the size of the subpopulation of persisting $M$. leprae was not clear. Therefore, the planning committee recommended that THELEP undertake controlled clinical trials of various combined drug regimens, in the course of which trials TR mice would be inoculated in an attempt to detect persisting $M$. leprae. In April 1977, at the first meeting of the THELEP Scientific Working Group (SWG), a draft Standard Protocol for Chemotherapy Trials in Lepromatous Leprosy was revised and adopted. ${ }^{29 *}$

\section{Standard Protocol}

The Standard Protocol envisages trials among 3 groups of lepromatous (LL and LI) patients: 1, those without prior treatment; 2 , patients who have relapsed, and whose Mycobacterium leprae have been proved resistant to dapsone; and 3, patients who have responded to dapsone monotherapy, and who may therefore be presumed to harbour dapsone-resistant subpopulations larger than those in previously untreated patients. The trials must comply with the ethical requirements of the World Health Organization; ${ }^{4}$ approval of governmental or institutional authorities and consent of the patients are to be obtained, and patients are to be closely monitored for the occurrence of adverse reactions to the drugs employed in the trials.

Enough patients of the appropriate group are to be recruited into the trial so that complete data will be available on at least 30 per regimen. Patients should have LL or LI leprosy, may be of either sex, and should be at least 15 years of age. To be excluded from the trial are pregnant women, patients with a Mitsuda

* Copies of the Standard Protocol for Chemotherapy Trials in Lepromatous Leprosy may be obtained by application to the Leprosy Unit, World Health Organization, Geneva, Switzerland. 
reaction equal to or greater than $3 \mathrm{~mm}$ in diameter, patients with tuberculosis requiring treatment, and those with a recent history of erythema nodosum leprosum (ENL), which may indicate recent, effective treatment, and which is often associated with failure of the patient's $M$. leprae to infect mice.

\section{EXAMINATIONS AT INTAKE}

When the patient is first considered for admission into a trial to be conducted among previously untreated patients, he is examined for the presence of lesions suggesting previous treatment, interrogated with respect to prior treatment, and a urine specimen is obtained for dapsone assay to exclude recent intake of the drug. Upon admission, two skin lesions, each large enough to permit repeated biopsies, are biopsied, and the specimens are divided, 1 portion of each being immediately fixed and submitted for histopathological examination; the remaining portions are placed at $0-4^{\circ} \mathrm{C}$, and submitted within 1 week for enumeration of $M$. leprae and inoculation of mice; the organisms from the specimen containing the larger number of $M$. leprae are to be inoculated into mice for determination of viability and of susceptibility to dapsone. The patient is then assigned by random allocation to a treatment regimen.

Following admission to the trial, a complete medical history is obtained, and a physical examination is performed, with emphasis on those points of the examination that are particularly relevant to leprosy. A lepromin test is performed, employing a standard preparation of lepromin. Smears for measurement of the bacteriological index (BI) are made from both ears and from other sites, and a 'nose blow' is obtained. Finally, specimens of urine, faeces and blood are obtained, and haematologic studies, studies of liver function and other laboratory tests are performed. Patients with syphilis or heavy burdens of parasites are to be treated prior to initiating treatment of leprosy by the trial regimen.

EXAMINATIONS DURING THE TRIAL

At intervals during treatment, a number of tests are carried out, as shown in Figure 1. Every 4 weeks the patient is examined briefly by the clinical investigator, note is made of any changes in the patient's lesions, and he is interviewed for symptoms suggesting adverse reactions to drugs. At this same interval, specimens of urine and blood are obtained for laboratory investigation. A 'nose-blow' specimen is obtained after 4 weeks of treatment. Finally, the occurrence of ENL and other leprosy reactions is recorded, and the reactions are treated appropriately.

After treatment for 12 weeks, a formal clinical assessment is performed. A biopsy is performed from the lesion found earlier to yield the larger number of $M$. leprae, for histopathological examination and for inoculation of both immunolo- 


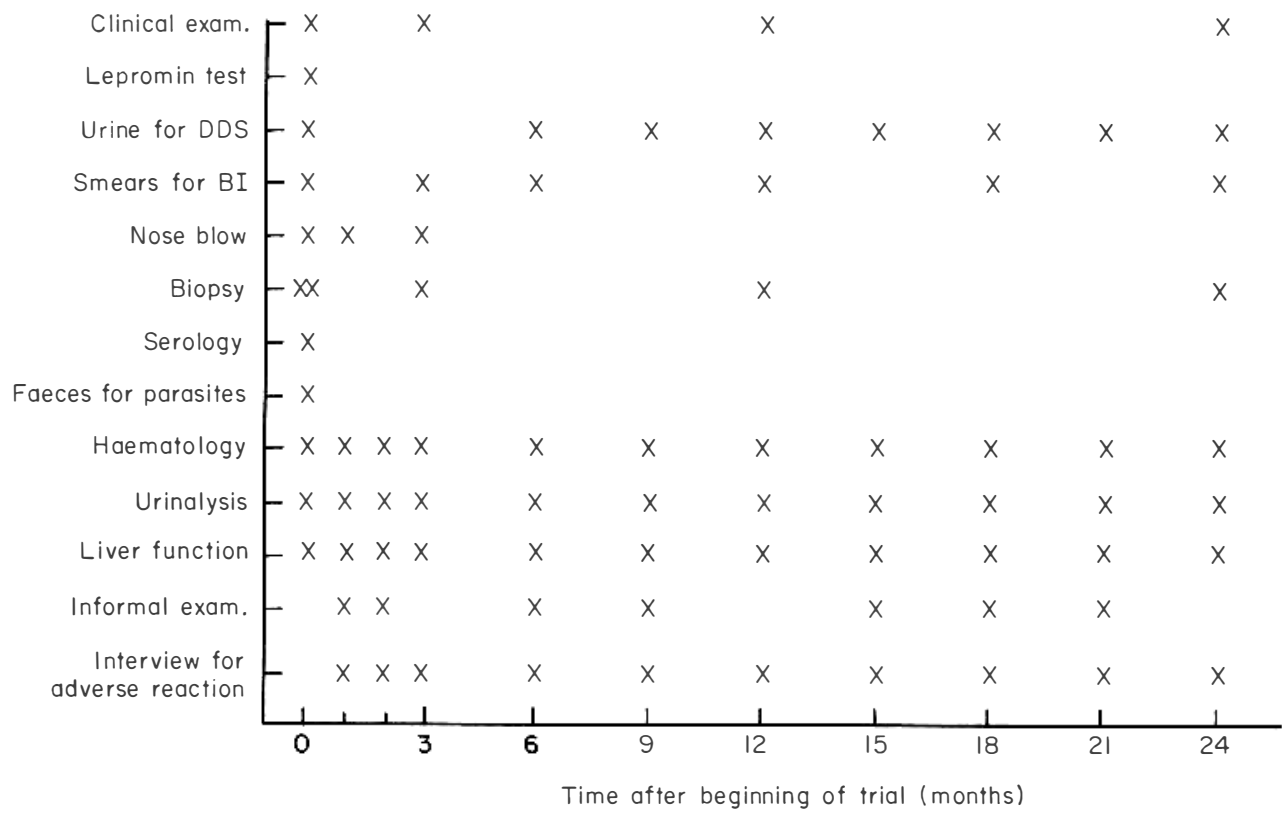

Figure 1. Schedule of examinations required by the Standard Protocol, showing minimal frequency.

gically normal mice (with 5000-10,000 organisms per foot-pad) and thymectomized-irradiated (TR) mice (with 100,000 M. leprae per foot-pad). Skin smears are made from the same 6 sites employed earlier, and a 'nose-blow' specimen is obtained.

At intervals of 3 months, beginning after 6 months of treatment, a urine specimen is obtained for dapsone assay as a guide to the regularity with which the patient takes his prescribed medication, the patient is examined for evidence of ENL and a change in his disease process, and he is interviewed for symptoms suggesting adverse reactions to his drugs. In addition, at intervals of 6 months, beginning after 6 months of treatment, smears are obtained for measurement of the BI, and specimens of urine and blood are obtained for laboratory study.

After 12, and again after 24 months of treatment, in addition to those procedures carried out at intervals of 3 and 6 months, a complete examination is performed, and a biopsy is performed for histopathologic examination and to provide organisms for inoculation of TR mice.

Patients may be removed from the trial by the responsible clinician for only a limited number of reasons: 1, onset of an important intercurrent illness; 2, evidence of clinically important drug allergy or toxicity; 3 , ENL so severe as to require cessation of therapy; 4 , pregnancy; and 5, the patient's desire to withdraw from the trial.

The patient may be removed from the trial, or the results of his study may be excluded from analysis by the THELEP Clinical Trials Subcommittee because 
the $M$. leprae recovered from the pretreatment biopsy specimen either fail to infect mice, or are shown to be resistant to dapsone, or because of clinical worsening or relapse of his leprosy.

\section{COMPARISON OF REGIMENS}

In essence, the THELEP Standard Protocol for Chemotherapy Trials in Lepromatous Leprosy calls for treatment by a combined drug regimen for a period of 2 years. Normal mice are inoculated with $M$. leprae recovered before the start of treatment, and again after treatment for 3 months, providing an opportunity to measure the initial rate at which the patient's $M$. leprae are killed. The single biopsy performed after 3 months' treatment obviously cannot permit a precise estimate of this rate, but should suffice to exclude the possibility that members of the drug combination so antagonize each other as greatly to decrease this initial rate of bacterial killing. TR mice are inoculated af ter treatment for 3 , 12 and 24 months, thus providing 3 opportunities for the detection of persisting $M$. leprae. The trial regimens will be compared in terms of the frequency with which persisting $M$. leprae are detected.

\section{THELEP controlled clinical trials}

At the time that it reviewed the THELEP Standard Protocol, the SWG suggested a number of combined-drug regimens to be tried among patients of the 3 groups. At its first meeting, immediately after the meeting of the SWG, the steering committee of the THELEP SWG selected the Institut Marchoux, Bamako, Mali, and the Central Leprosy Teaching and Research Institute, Chingleput, South India, as the sites of the first 2 trials. The trials themselves were to be carried out as a collaborative effort with participation of several investigators from different parts of the world. The trials were to be carried out among previously untreated patients with leprosy classified as LL or LI according to the Ridly-Jopling classification. ${ }^{15}$

Recruitment of patients for the trials was begun in Chingleput in August 1977, and in Bamako in November of that year. The regimens under trial are, at Chingleput: 1, regimen $\mathrm{A}_{1}$-dapsone, $100 \mathrm{mg}$, rifampicin, $600 \mathrm{mg}$, and clofazimine, $100 \mathrm{mg}$, each drug administered daily for 2 years; 2 , regimen $\mathrm{C}-\mathrm{a}$ single initial 1500-mg dose of rifampicin, together with dapsone, $100 \mathrm{mg}$, administered daily for 2 years; and 3 , regimen $\mathrm{D}_{1}$ - as for regimen $\mathrm{C}$, with the addition of clofazimine administered in a daily dose of $100 \mathrm{mg}$ for the first 3 months.

In Bamako, the regimens under testare: 1 , regimen $\mathrm{A}_{2}$ - as for regimen $\mathrm{A}_{1}$, but with prothionamide, $500 \mathrm{mg}$, in place of clofazimine; 2 , regimen $\mathrm{C}$ - as for Chingleput; and 3, regimen $\mathrm{E}_{2}$ - dapsone, $100 \mathrm{mg}$ daily for 2 years, rifampicin, $900 \mathrm{mg}$ once weekly for the first 3 months; and prothionamide, $500 \mathrm{mg}$ daily for the first 3 months. 
At the same time, the steering committee elected to defer controlled trials of chemotherapy among patients of groups 2 and 3. It would have been difficult to assemble numbers of lepromatous patients who had relapsed with the emergence of dapsone-resistant $M$. leprae, and who had not been started on treatment with alternate drugs. Patients who had responded well to dapsone monotherapy were undoubtedly available in larger numbers even than previously untreated patients. However, their $M$. leprae were certain to be non-infective for mice, even before treatment with a combined drug regimen had been initiated, and they would not have formed a homogeneous group with respect to duration of prior treatment.

The regimens to be studied in the 2 trials were selected, not because they were felt to be the most suitable for use in leprosy control programmes, but because it was believed important to study the eff ects on persisting $M$. leprae of treatment by these regimens. Moreover, although it is clear that elimination of persisting $M$. leprae may not be identified with 'cure' of lepromatous leprosy, the THELEP SWG thought that trials of combined chemotherapy in which persisting $M$. leprae were sought would more quickly provide answers to the very urgent questions about combined-drug regimens than would trials having relapse of the patient as their end-point. Moreover, the SWG did not believe it ethical in 1977 to plan trials in which chemotherapy of patients with lepromatous leprosy was deliberately stopped.

Data attesting to acceptably low relapse rates of lepromatous leprosy following many years of dapsone as supervised monotherapy, or a few years of chemotherapy with a combination of drugs that included rifampicin and prothionamide, became available in early 1979. And at its second meeting, in April 1979, the SWG decided to undertake trials of combined chemotherapy among large numbers (500-1000) of lepromatous patients whose BI's had fallen to 0 after at least 5 years of dapsone monotherapy. Intensive combined-drug regimens are to be administered for 2 years, after which, active therapy is to be withdrawn and the patients observed for evidence of relapse. Such trials will require much more time than those described in this report. But they possess the advantage of having cure of lepromatous leprosy as their end-point.

An entirely unexpected result of these 2 trials has been the demonstration of high prevalences of primary dapsone resistance among lepromatous patients at both trial sites. This is described in detail in the accompanying paper. ${ }^{21}$ Other publications of the results of these trials are planned.

\section{References}

1 Collaborative effort of the US Leprosy Panel (US-Japan Cooperative Medical Science Program) and the Leonard Wood Memorial. Rifampicin therapy of lepromatous leprosy. Amer J Trop Med Hyg, 1975; 24: 475-84.

2 Collaborative effort of the US Leprosy Panel (US-Japan Cooperative Medical Science Program) 
and the Leonard Wood Memorial. Spaced clofazimine therapy of lepromatous leprosy. Amer J Trop Med Hyg, 1976; 25: 437-44.

${ }^{3}$ Committee on Experimental Chemotherapy. Experimental chemotherapy in leprosy. Bull WHO, 1976; 53: 425-33.

${ }^{4}$ Proposed International Guidelines for Biomedical Research Involving Human Subjects. Geneva: Council for International Organizations of Medical Sciences, 1982.

${ }^{5}$ Faget GH, Pogge RC, Johansen FA, Dinan F, Prejean BM, Eccles CG. The promin treatment of leprosy. A progress report. Publ Health Rep, 1943; 58: 1729-41.

${ }^{6}$ Gelber RH, Waters MFR, Pearson JMH, Rees RJW, McDougall AC. Dapsone alone compared with dapsone plus rifampicin in short-term therapy of lepromatous leprosy. Le pr Rev, 1977; 48: $223-9$.

7 Levy L, Shepard CC, Fasal P. Clofazimine therapy of lepromatous leprosy caused by dapsone-resistant Mycobacterium leprae. Amer J Trop Med Hyg, 1972; 21: 315-21.

${ }^{8}$ Levy L, Shepard CC, Fasal P. The bactericidal effect of rifampicin on M. leprae in man: a) single doses of 600, 900 and $1200 \mathrm{mg}$; and b) daily doses of $300 \mathrm{mg}$. Int J Lepr, 1976; 44: 183-7.

9 Pearson JMH. The problem of dapsone-resistant leprosy. Int J Lepr, 1981; 49: 417-20.

${ }_{10}$ Pearson JMH, Pettit JHS. Chemotherapeutic trials in leprosy. 7. Trial of $50 \mathrm{mgm}$. DDS twice weekly in the treatment of lepromatous leprosy. Int J Lepr, 1969; 37: 40-5.

11 Pettit JHS, Rees RJW. Chemotherapeutic trials in leprosy. 4. Dapsone (DDS) in low dosage in the treatment of lepromatous leprosy. A demonstration pilot-study. Int $J$ Lepr, 1967; 35: $140-8$.

12 Pettit JHS, Rees RJW, Ridley DS. Chemotherapeutic trials in leprosy. 3. Pilot trial of a riminophenazine derivative, B.663, in the treatment of lepromatous leprosy. Int J Lepr, 1967; 35: $25-33$.

13 Rees RJW. Enhanced susceptibility of thymectomized and irradiated mice to infection with Mycobacterium leprae. Nature, 1966; 211: 657-8.

14 Rees RJW, Waters MFR, Pearson JMH, Helmy HS, Laing ABG. Long-term treatment of dapsone-resistant leprosy with rifampicin: clinical and bacteriological studies. Int $J$ Lepr, 1976; 44: 159-69.

15 Ridley DS, Jopling WH. Classification of leprosy according to immunity. A five-group system. Int J Lepr, 1966; 34: 255-73.

16 Shepard CC. The experimental disease that follows the injection of human leprosy bacilli into foot-pads of mice. J Exp Med, 1960; 112: 445-54.

17 Shepard CC, Levy L, Fasal P. The death of Mycobacterium leprae during treatment with 4,4'-diaminodiphenysulfone (DDS). Amer J Trop Med Hyg, 1968; 17: 769-75.

18 Shepard CC, Levy L, Fasal P. The death rate of Mycobacterium leprae during treatment of lepromatous leprosy with acedapsone (DADDS). Amer J Trop Med Hyg, 1972; 21: 440-5.

19 Shepard CC, Levy L, Fasal P. Rapid bactericidal effect of rif ampicin on Mycobacterium leprae. Amer J Trop Med Hyg, 1972; 21: 446-9.

20 Shepard CC, Levy L, Fasal P. Further experience with the rapid bactericidal effect of rifampicin on Mycobacterium leprae. Amer J Trop Med Hyg, 1974; 23: 1120-4.

${ }^{21}$ Subcommittee on Clinical Trials. Primary resistance to dapsone among untreated lepromatous patients in Bamako and Chingleput. Lepr. Rev., 1983; 54: 177-183.

${ }^{22}$ Toman K. Bacterial persistence in leprosy. Int J Lepr, 1981; 49: 205-17.

23 Waters MFR. Chemotherapeutic trials in leprosy. 1. Comparative trial of macrocyclon plus dapsone and dapsone alone in the treatment of lepromatous leprosy. Lepr Rev, 1963; 34: 173-92.

${ }^{24}$ Waters MFR. Chemotherapeutic trials in leprosy. 6. Pilot study of the riminophenazine derivative B.663 in low dosage (100 mg twice weekly) in the treatment of lepromatous leprosy. Int J Lepr, 1968; 36: 391-9. 
${ }^{25}$ Waters MFR, Pettit JHS. Chemotherapeutic trials in leprosy. 2. Comparative trial of dapsone plus ditophal (etisul) and dapsone alone in the treatment of lepromatous leprosy. Int J Lepr, 1965; 33: 280-96.

26 Waters MFR, Rees RJW. Changes in the morphology of Mycobacterium leprae in patients under treatment. Int J Le pr, 1962; 30: 266-77.

27 Waters MFR, Rees RJW, McDougall AC, Weddell AGM. Ten years of dapsone in lepromatous leprosy: clinical, bacteriological and histologic assessment and the finding of viable leprosy bacilli. Lepr Rev, 1974; 45: 288-98.

28 Report of the Planning Meeting for the THELEP Task Force. World Health Organization Publication TDR/THELEP/76.1, 1976.

29 Standard Protocol for Chemotherapy Trials in Lepromatous Leprosy. World Health Organization Publication TDR/SWG-THELEP (1)/77.3, Annex 1, 1977. 